\title{
Redesenhando caminhos na direção da clínica ampliada de saúde bucal'
}

\section{Redesigning pathways towards the expanded oral health clinic}

Graciela Soares Fonsêca ${ }^{\mathrm{a}}$

aniversidade Federal da Fronteira Sul. Chapecó, SC, Brasil. E-mail: graciela.fonseca®uffs.edu.br

\section{Fabiana Schneider Pires ${ }^{b}$}

bUniversidade Federal do Rio Grande do Sul. Faculdade de Odontologia. Departamento de Odontologia Preventiva e Social. Porto Alegre, RS, Brasil.

E-mail: fabianaspiresळgmail.com

\section{Simone Rennó Junqueirac}

'Universidade de São Paulo. Faculdade de Odontologia. Departamento de Odontologia Social. São Paulo, SP, Brasil. E-mail: srjळusp.br

\section{Carolina Rogel de Souza ${ }^{d}$}

¿Universidade Federal de Santa Catarina. Departamento de Fonoaudiologia. Florianópolis, SC, Brasil.

E-mail: carolrogelळyahoo.com.br

\section{Carlos Botazzo}

eUniversidade de São Paulo. Faculdade de Saúde Pública. Departamento de Política, Gestão e Saúde. São Paulo, SP. Brasil. E-mail: botazzo®usp.br

\section{Correspondência}

Graciela Soares Fonseca

Rodovia SC 484, Fronteira Sul, Bloco dos Professores, sala 317.

Chapecó, SC, Brasil. CEP 89815-899.

\section{Resumo}

O trabalho analisa a experiência da clínica ampliada de saúde bucal em uma Unidade Básica de Saúde (UBS) do município de São Paulo. O estudo é de abordagem qualitativa, do tipo pesquisa-ação, em que cirurgiãs-dentistas e estagiários de odontologia experienciaram a clínica ampliada de saúde bucal, realizando registros sobre suas práticas em diários de pesquisa e construindo, em conjunto com os usuários, projetos terapêuticos singularizados. Foram analisados três diários de pesquisa e 52 casos clínicos e seus respectivos projetos terapêuticos singularizados, elaborados entre os anos de 2014 e 2015. O material foi tratado por análise de conteúdo temática, com as seguintes categorias: procedimentos odontológicos realizados na atenção primária à saúde; referência e contrarreferência; divisão do trabalho; anamnese e satisfação do usuário. A análise indicou que novos processos de trabalho estimulam os usuários a expor suas demandas de saúde e que projetos terapêuticos singularizados são fundamentais para a produção do cuidado, o que gera satisfação e resolubilidade. As principais limitações encontradas foram: pouco apoio da rede especializada, escassez de pessoal auxiliar, não acesso ao prontuário único e dificuldade em ressignificar as narrativas para além dos achados bucais. Torna-se essencial o desenvolvimento de estudos relacionados a novos fazeres em saúde bucal em outras realidades.

Palavras-chave: Atenção Primária à Saúde; Acolhimento; Saúde Bucal; Inovação.

10 projeto de pesquisa do qual o estudo derivou foi financiado pelo Conselho Nacional de Desenvolvimento Científico e Tecnológico (CNPq), edital MCTI/CNPq/MS-SCTIE-Decit nº 10/2012 e Fapesp- 2013/116682. 
This article aims at analyzing the experience of an Expanded Oral Health Clinic in a Basic Health Unit (BHU) in the city of São Paulo. This study has a qualitative approach, of the research-action type, in which dental surgeons and trainees experienced an Expanded Clinic of oral health, recording their practices in research diaries and devising singularized therapeutic projects together with patients. We analyzed o3 research diaries and 52 therapeutic projects produced from 2014 to 2015 . The material was processed through thematic content analysis, with the following categories: dental procedures in the Primary Health Care; reference and counter-reference; work division; anamnesis, and user satisfaction. Our analysis indicated that new work processes stimulate patients to expose their health demands, and that therapeutic projects are imperative for the production of care, thus generating satisfaction and solvability. The difficulties of a subjectcentered clinic were: little support from the specialized network, lack of auxiliary personnel, non-access to a single health records, and difficulty in re-signifying narratives to go beyond the oral cavity findings. Further studies, related to new oral health practices in other realities, are essential. Keywords: Primary Health Care; User Reception; Oral Health; Innovation.
A necessidade de garantir que os princípios do Sistema Único de Saúde (SUS) - universalidade, equidade e integralidade - sejam efetivados no cotidiano das práticas, sobretudo no contexto da atenção primária à saúde (APS), vem induzindo os atores do sistema a (re)inventarem dispositivos de cuidado no sentido de proporcionar maior resolubilidade e qualidade. Nesse contexto, as discussões sobre abordagens centradas nos sujeitos merecem destaque e ganham cada vez mais espaço.

Na contramão desse processo, as práticas odontológicas - a despeito das inovações propostas pela Política Nacional de Saúde Bucal (PNSB), promulgadas em 2004 - se mantêm como "cárieorientadas" ou "cárie-dirigidas", configurando-se, ainda na atualidade, como pouco resolutivas e mutiladoras (Botazzo, 2013), além de não terem adquirido capilaridade no cotidiano dos serviços de saúde (Soares et al., 2011).

O trabalho em saúde bucal permanece intimamente ligado - e às vezes confundido - com o tecnicismo odontológico, alheio aos esforços de aproximar-se de um modelo de vigilância e promoção da saúde. 0 âmbito coletivo quase sempre é reduzido aos conceitos positivistas de diminuição dos índices epidemiológicos e aos indicadores operacionais e de gestão, como a cobertura da primeira consulta odontológica programática, a cobertura de ação coletiva de escovação dental supervisionada, a média de procedimentos odontológicos básicos individuais e a proporção de procedimentos odontológicos especializados em relação às ações odontológicas individuais (Botazzo, 2013; Soares et al., 2011).

Portanto, os arranjos tecnológicos propostos pela PNSB, dito inovadores, não se distinguem, em essência, dos modelos que vigoraram antes dela. Ainda que as diretrizes da PNSB considerem ações por ciclos de vida - crianças, bebês, gestantes e, mais recentemente, idosos -, elas persistem no centramento dentário e na busca incessante por lesões de cárie e inflamações gengivais, propondo-se permanentemente - em abrangência universal - a escovação dentária como plataforma básica para processar a educação em saúde(Pires; Botazzo, 2015). 
Justifica-se pelo fato de as ações em saúde bucal terem como modelo a profissão odontológica e esta ser (re)conhecida pelo modo prático como organiza a relação com seu paciente. A representação que existe é a do paciente acomodado na cadeira odontológica, com a boca aberta, tendo dentes inspecionados, ausências dentárias notadas, lesões observadas nos tecidos periodontais etc. O odontograma, representação máxima do centramento dentário e ícone do exame odontológico, é o instrumento para registro de alterações dentárias, de forma cifrada, acessível àqueles com conhecimento técnico suficiente para preenchê-lo. É também indicador de diagnóstico e terapêutica, o que evidencia o caráter “odontologizado" das práticas (Botazzo et al., 2015).

Assim, torna-se imperativo buscar referenciais e meios que aportem práticas inovadoras capazes de efetivar a PNSB no cotidiano do trabalho em saúde, em especial no âmbito da APS, que, em sua essência, é voltada para o cuidado às pessoas, não às doenças. Assim, precisa ser acessível, abrangente, contínua e também garantir a coordenação do cuidado, caso o problema demande encaminhamento para outros serviços (Petersen, 2014; Starfield, 2011).

No início da década de 1990, o conceito de cuidados centrados na pessoa (CCP) passou a ser largamente utilizado em escala internacional, particularmente no Canadá (Stewart et al., 2010; Walji; Karimbux; Spielman, 2017). Os CCP estruturam-se de modo a respeitar os valores, preferências e necessidades das pessoas, coordenando o cuidado em consonância com os desejos dos usuários e das famílias, pautado em boa comunicação, continuidade do cuidado e apoio físico, moral e emocional. A pessoa é colocada no centro das ações, participando das decisões e sendo corresponsabilizada pelo seu cuidado (Petersen, 2014; Walji; Karimbux; Spielman, 2017).

No contexto da odontologia, as discussões relacionadas aos CCP vêm sendo aprofundadas. O conceito é visto, pela Associação de Educação Odontológica na Europa, como essencial à formação em odontologia (Manogue et al., 2011) e, no Canadá, desde 2012, como uma área de competência indispensável para a formação (ACFD, 2016). Além disso, os CCP aparecem em destaque no documento da American Dental Education Association (Adea), apontado como modelo dominante ideal dos sistemas de saúde (Palatta et al., 2017). No entanto, as dificuldades para implementação dessa prática são numerosas, destacando-se a dicotomia corpo-boca (Botazzo, 2013) e a formação fragmentada e departamentalizada, centrada na técnica (Rosenzweig et al., 2016), o que dificulta o desenvolvimento de competências de comunicação e cuidado integral.

Existem, na literatura, experiências de ensino de odontologia focado nos CCP. Na escola de medicina de Harvard, por exemplo, há um esforço para que a formação seja direcionada para os cuidados integrais, em detrimento da clínica organizada com base em procedimentos (Park; Howell, 2015). Da mesma forma, a Universidade McGill desenvolveu um modelo de ensino clínico pautado na humanização (Apelian; Vergnes; Bedos, 2014) e a Faculdade de Odontologia de Toulouse, na França, oferece um curso com CCP focados no desenvolvimento de habilidades interpessoais, como a escuta ativa e a empatia (Rosenzweig et al., 2016). No Brasil, algumas faculdades de odontologia estão direcionando esforços para promover uma formação em que os usuários ocupem o centro do atendimento (Hayacibara et al., 2012).

Alinhado à compreensão dos $\mathrm{CCP}$, o conceito de clínica ampliada vem sendo formulado e discutido no Brasil sob grande influência das propostas de Campos (2003) relacionadas à metodologia do apoio Paideia. Em 2003, o Ministério da Saúde incluiu a concepção de clínica ampliada na Política Nacional de Humanização (PNH) para contribuir com a transformação dos modelos de atenção e gestão no SUS (Brasil, 2008), o que permitiu "maior compreensão" sobre a clínica ampliada, sobretudo no que se refere à sua "utilização prática".

Ampliar a clínica denota desviar o foco normalmente voltado para doenças e procedimentos para o sujeito, com sua doença, em sua singularidade, focando demandas e necessidades (Campos et al., 2014). Essa clínica pauta-se na escuta e reconhece o saber, o desejo e o interesse do outro - levando em consideração a situação de vida de cada pessoa -, prescrevendo menos e negociando mais, buscando a integralidade sem desconsiderar avanços tecnológicos, qualificação técnica e a prática baseada em evidências científicas como responsabilidade 
de todos os profissionais de saúde que compõem a equipe (Brasil, 2008; Campos, 2003).

A clínica ampliada requer, ainda, o reconhecimento dos limites inerentes às práticas e tecnologias do trabalho em saúde (Brasil, 2008), exigindo a utilização de tecnologias leves de cuidado (Merhy, 2013).

Na saúde bucal, a clínica ampliada e os CCP encontram suporte teórico no conceito de bucalidade, visto que ele permite ultrapassar a limitação das práticas direcionadas à doença, apontando a insuficiência das teorias odontológicas para recuperar o homem por inteiro (Botazzo, 2013) e a influência dos determinantes sociais no adoecimento (Glick et al., 2017; Sabato et al., 2018; Watt; Sheiham, 1999).

Baseados neste referencial, pesquisadores elaboraram um modelo de atendimento centrado na pessoa, denominado "clínica ampliada de saúde bucal”, e o aplicaram em uma Unidade Básica de Saúde (UBS) do município de São Paulo entre 2014 e 2015. Este manuscrito tem por escopo analisar essa experiência.

\section{Trajetória metodológica}

Este estudo é de abordagem qualitativa, caracterizado como pesquisa-intervenção, do tipo pesquisa-ação (Pezzato; L’Abbate, 2012). O recorte que compõe o projeto multicêntrico intitulado "Projeto inovação na produção do cuidado em saúde bucal: possibilidades de uma nova abordagem na clínica odontológica para o Sistema Único de Saúde" foi desenvolvido com auxílio do Conselho Nacional de Desenvolvimento Científico e Tecnológico (CNPq) e da Fundação de Amparo à Pesquisa do Estado de São Paulo (Fapesp).

A partir do contexto apresentado de que a prática da saúde bucal deve ser propositiva de novos olhares e concepções e precisa ultrapassar processos de trabalho dirigidos por "patologias-mãe" - como a cárie -, os pesquisadores propuseram a uma UBS do município de São Paulo, cenário do estudo, um modelo de organização do setor de saúde bucal com novos fluxos e abordagens, compondo novas práticas em saúde bucal que potencialmente correspondessem à inovação pretendida pela PNSB, nos moldes da clínica ampliada e na perspectiva de uma tecnologia para os CCP, considerando as necessidades bucais, os desejos, a história, o cotidiano, as expectativas e a singular experiência viva e vivida dos atendidos (Botazzo et al., 2015; Pires; Botazzo, 2015).

Nessa lógica, a equipe de pesquisa experienciou o atendimento em clínica ampliada de saúde bucal, organizado a partir dos problemas bucais trazidos pelos usuários, esforçando-se na direção do "descentramento" dentário e na construção de casos clínicos e projetos terapêuticos compartilhados e singularizados (Barros; Botazzo, 2011; Botazzo et al., 2015). A equipe era composta por três cirurgiãs-dentistas e seis estudantes do curso de odontologia, que cursavam o último semestre de graduação em uma instituição pública de ensino e que permaneceram por períodos diferentes ao longo da investigação. As consultas aconteciam nos consultórios disponíveis, de médicos ou da enfermagem, seguindo os passos do método clínico e dispensando o uso do odontograma (Barros; Botazzo, 2011). Também foram realizadas atividades em grupo - modalidade denominada pela equipe de "anamnese coletiva" - com o intuito de viabilizar a escuta qualificada das queixas dos usuários, construindo narrativas de vida que permitissem a entrada em cena de outros elementos além dos aspectos clínico-bucais, privilegiando-se, então, as tecnologias leves-relacionais no encontro terapêutico (Merhy, 2013).

Durante o diálogo clínico e a escuta qualificada, buscou-se estabelecer um fluxo de conversas sobre questões que das características individuais que motivaram o paciente a comparecer à consulta. A premissa inicial era acolher o usuário, com sua subjetividade, sua queixa e suas histórias em um ambiente cordial e receptivo, ouvir suas angústias e ajudá-lo no depósito de suas necessidades e desejos (Campos et al., 2014).

Ao reunir os dados das avaliações clínicas com as significações apresentadas pelos usuários, foi possível elaborar casos clínicos e projetos terapêuticos singularizados, resultantes do encontro entre os desejos e as necessidades trazidos pelos usuários com a capacidade técnica instalada, o conhecimento clínico-cirúrgico da equipe de saúde e as limitações e potencialidades que esse processo 
intenso exige (Brasil, 2008; Doyle; Lennox; Bell, 2013; Shay; Lafata, 2015; Walji; Karimbux; Spielman, 2017).

Após a construção dos casos clínicos e projetos terapêuticos singularizados, os procedimentos clínicos foram realizados nas consultas que se seguiram até alcançar a resolução do quadro, sendo o usuário dispensado por meio da alta pactuada ou encaminhado para outros serviços. A equipe buscou realizar procedimentos clínicos para além do que a PNSB preconiza com vistas a reforçar o caráter resolutivo da APS.

A UBS que foi cenário da pesquisa conta com um consultório odontológico com três equipes completas, estrutura física adequada e boa disponibilidade instrumental e material de consumo. A inserção da equipe do projeto de pesquisa aconteceu no período ocioso (quando não havia equipe de saúde bucal atuando na UBS), por quatro horas semanais, com auxílio da técnica em saúde bucal (TSB) da unidade. A entrada no campo ocorreu em fevereiro de 2014, após pactuação do projeto de pesquisa com a coordenação da unidade e comunicação à equipe de saúde sobre as práticas que seriam desenvolvidas. A saída dos pesquisadores aconteceu em dezembro de 2015, com a conclusão dos casos clínicos antes do encerramento das atividades da equipe.

Os usuários atendidos foram agendados quando buscaram livremente o setor de saúde bucal ou em função de encaminhamentos realizados por outros profissionais da equipe de saúde. Todos eles residiam no território de abrangência da UBS e eram cadastrados no serviço.

Os pesquisadores e os estudantes que compuseram a equipe realizaram o registro da experiência em diários de pesquisa que continham, além da descrição dos acontecimentos, reflexões, notas de discussões feitas em grupo, análise dos casos etc., construindo uma "metáfora da realidade" em que estiveram imersos durante o estudo (Hess, 2006). Para Lourau (1993), o diário reflete o processo de pesquisa e permite maior aproximação dos futuros leitores com o trabalho de campo. Além disso, a escrita proporciona reflexões sobre o vivido, ocasionando desnaturalização da realidade (Lourau, 1993).

Para este recorte, foram analisados três diários de pesquisa redigidos por uma cirurgiã-dentista e dois estudantes. Os diários foram eleitos para integrar a análise em função da maior densidade e quantidade de registos presentes. Além disso, foram sistematizados os casos clínicos e projetos terapêuticos singularizados dos 52 usuários que foram atendidos no período de desenvolvimento do estudo.

O material foi analisado por intermédio da análise de conteúdo temática (Bardin, 2011). Inicialmente, procedeu-se à pré-análise com a leitura flutuante de todo o material para, na sequência, iniciar o processo de codificação, sendo atribuído para cada um dos três autores dos diários o nome de uma flor (Margarida, Orquídea e Violeta). Em seguida, o material empírico foi organizado nas seguintes categorias de análise: (1) procedimentos odontológicos realizados na APS; (2) referência e contrarreferência; (3) divisão do trabalho; (4) anamnese; e (5) satisfação do usuário.

0 projeto de pesquisa foi iniciado após aprovação do Comitê de Ética em Pesquisa da Faculdade de Odontologia da Universidade de São Paulo, por meio do parecer $n^{0} 501.069 / 2014$ e todos os participantes consentiram, de modo livre e esclarecido, sua inclusão no estudo, sendo garantido a eles confidencialidade e anonimato em relação aos dados coletados.

\section{Resultados e discussão}

A maioria dos usuários atendidos era do sexo feminino (63\%) e a faixa etária incluiu grupos com predominância de adultos e idosos com idade variando entre 45 e 69 anos (31\%). A maioria procurou o serviço de saúde bucal queixando-se de problemas com suas próteses dentárias - móveis e/ou fixas -, mobilidade e/ou desgaste dentários, dificuldade de mastigação e disfunção temporomandibular (DTM), além de dores periauriculares, suboccipitais, e, em menor incidência, de cárie dentária e doença periodontal. Também emergiram problemas de "estética" bucal. Ou seja, trata-se de uma realidade distinta que não se "encaixa" nas ações priorizadas pela PNSB ou pelo sistema de informação, enquadrando-se para além do "habitus" odontológico, mas com igual ou maior grau de "rompimento de normalidade", afetando a funcionalidade da vida dos sujeitos.

Esses achados reforçam a possibilidade de o usuário, no nível primário da atenção, ser um 
paciente crônico, o que revela outros desafios quando se pensa a gestão da cronicidade (Mendes, 2010; Starfield, 2011), em geral instalada num quadro de comorbidades bucais e sistêmicas que exige conhecimentos, competências e atitudes para além do domínio técnico (Botazzo, 2013, 2017).

No encontro com os usuários foram abordadas questões sociais e familiares, que tomaram centralidade e mostraram-se potentes para proporcionar maior compreensão sobre a vida de cada sujeito e oferecer maiores significados à abordagem terapêutica planejada. Em consonância, estudos evidenciam que os CCP apresentam maior capacidade para responder às demandas dos sujeitos e alcançar soluções favoráveis (Starfield, 2011; Stewart et al., 2010). A compreensão dos determinantes sociais de saúde (DSS) é essencial para otimizar os resultados do cuidado em saúde; naturalmente, essa não é uma prática rotineira nos serviços de saúde bucal (Sabato et al., 2018).

De forma menos estruturada, foi possível captar nos casos clínicos a transversalidade de alguns sentimentos, como vergonha decorrente de mutilações bucais e transtornos mentais (síndrome do pânico, ansiedade, depressão, distúrbios do sono ou insônia). Esses são problemas que, quando mais bem compreendidos, podem favorecer abordagens voltadas para a integralidade (Barros; Botazzo, 2011).

Ao construir o projeto terapêutico de forma compartilhada com o usuário, dentro das possibilidades de cada envolvido, foi possível encontrar respostas às necessidades de saúde bucal dos sujeitos em poucas horas clínicas, ou seja, de maneira resolutiva. Para 58\% dos atendidos, foram necessárias até duas "visitas" ao serviço - consulta inicial e retorno - para resolver o problema trazido nos encontros.

Entende-se que as ações de saúde devem ser traduzidas em ações efetivas, que satisfaçam os usuários com procedimentos eficazes diante do conjunto de problemas de saúde identificados (Merhy, 1999). Resolubilidade está associada à implantação de novos serviços e de novos equipamentos, à incorporação de novas tecnologias, à reorganização de processos de trabalho, à conformação de redes, além da articulação e complementaridade de serviços e redes existentes. O cuidado em saúde deve orientar-se pela atenção ao outro e não por fatores externos ao encontro terapêutico, como a técnica, a rotina, o protocolo, a profissão ou mesmo a instituição (Ceccim; Merhy, 2009).

Esses dados corroboram achados de natureza semelhante em uma investigação que, igualmente, tomou a clínica ampliada de saúde bucal como marco teórico e apoiou-se na investigação do conteúdo prático que o conceito de bucalidade poderia exprimir, notando-se a emergência do sujeito e a expressão do seu sofrimento bucal. Nesse caso, a escuta qualificada e o caso clínico, constituídos na anamnese, permitiram perceber que a programação em saúde, com foco na cárie dentária e em um elenco bastante restrito de possibilidades para o adoecimento bucal, definidas a priori, não consegue funcionar como captadoras ou mesmo servem como "endereço" para o amparo das necessidades dos sujeitos que procuram a ajuda do serviço de saúde (Barros; Botazzo, 2011).

Registrada essa contextualização inicial, passase à apresentação e discussão das categorias de análise que representam a síntese do aparato das significações registradas pelos sujeitos nos diários de pesquisa e nos casos clínicos e projetos terapêuticos sistematizados.

A primeira categoria refere-se aos procedimentos odontológicos realizados na APS. Esse tema foi recorrente nos diários de pesquisa em função da inquietação da equipe quanto à resolubilidade e não convergência entre necessidade e prática programática (Pires; Botazzo, 2015). A seguir, registram-se fragmentos dos diários de pesquisa que demonstram como procedimentos distintos daqueles listados pela PNSB foram incorporados à prática clínica no cenário de estudo:

Acreditamos que a inovação também deve estar aí, ou seja, é preciso inovar nos procedimentos da atenção básica para garantir resolubilidade e integralidade, evitando que o paciente passe meses aguardando a vaga no $C E O$ [Centro de Especialidades Odontológicas], com a sua mutilação dentária aparente. (Orquídea)

'[A paciente] queixava-se das próteses não pararem em sua boca. Observo falta de rebordo inferior. 
Faço reembasamento com pasta Lysanda. [...] fica feliz com o procedimento efetuado, parece que teve atenção, teve resolução naquele momento. (Margarida)

Nessemesmo dia, também aprendi a reconstruir coroas com resina fotopolimerizável, utilizando uma matriz de acetato [...]. Eu não conhecia essa técnica e achei o procedimento simples, fácil e rápido, completamente passivel de ser desenvolvido nas unidades básicase capaz de reabilitar o paciente. (Orquídea)

A maneira como esses casos foram conduzidos pela equipe, compondo percursos possíveis com o sujeito-usuário, demonstra a necessidade de rever os protocolos de saúde bucal na APS, adequando-os às necessidades de saúde dos sujeitos e diversificando o repertório de ações oferecidas (Campos et al., 2014).

Em decorrência desse entendimento e por colocar as necessidades e os desejos dos usuários como fios condutores do trabalho na saúde bucal, os pesquisadores incluíram outros procedimentos clínicos nas práticas desenvolvidas, dentre eles: reembasamento e reparo de próteses fixas e removíveis, reconstrução de coroas e restaurações estéticas, exodontias de terceiros molares, biópsias e remoção de lesões benignas. 0 intuito era reforçar o papel do nível primário da atenção na coordenação do cuidado em saúde e na resolução da maior parte das demandas (Mendes, 2010; Starfield, 2011).

Foi notável, ainda, a necessidade de reavaliar a organização da média complexidade em saúde bucal, bem como os mecanismos para referenciar e contrarreferenciar os usuários e os protocolos de encaminhamento de cada especialidade, sendo essa a segunda categoria de análise. No cenário de estudo, esse foi um dos grandes impasses para alcançar a integralidade do cuidado, como revelam os casos clínicos, uma vez que para a unidade de saúde em questão não havia uma referência claramente definida e pactuada. Para algumas especialidades, como prótese total, não foram encontrados impedimentos ou filas, mas para outras, como endodontia, prótese parcial e semiologia, o acesso foi irregular, inconsistente, permeado por pactuações individuais e encaminhamentos frágeis, eximindo da APS o seu papel de ordenadora do cuidado na rede de atenção à saúde (RAS).

Estudos apontam para a necessidade de estabelecer protocolos que regulem melhor a referência e a contrarreferência em saúde bucal com vistas a ampliar o acesso e qualificar a atenção prestada (Martelli et al., 2008; Souza et al., 2015), corroborando os achados deste trabalho. Outra questão importante refere-se à ausência de referência para alguns tipos de demanda, como a confecção de próteses fixas e a reabilitação para DTM.

Os diários de pesquisa ilustram alguns impasses relacionados a essa categoria:

Me angustiou muito a minha impotência diante da situação dela. Primeiro porque o dente parecia estar infeccionado e eu fiquei insegura em relação à recimentação da prótese. [...]. Em segundo lugar, me angustia não poder resolver a má oclusão dessa mulher. $O$ caso dela não se encaixa no protocolo de encaminhamento da atenção básica para o CEO. [...] o que D. M. fará? (Orquídea)

A referência tem sido um caminho obscuro para nós. Fizemos alguns encaminhamentos para o CEO e tivemos informações de que alguns pacientes já foram atendidos. No entanto, eles se restringem aos casos de prótese (surpreendentemente!). Temos um caso de estomatologia que não conseguiu ser agendado pelo sistema por conta de problemas burocráticos com nosso registro na UBS. Enfim, [...] gostaria de frisar a dificuldade para implementar um processo de trabalho pautado na integralidade e no sujeito. Uma clínica ampliada não pode ser constituída ou sustentada com tanta burocracia! Com relação à contrarreferência, ainda não recebemos nenhum caso. (Orquídea)

A paciente tinha o dente 38 com cárie extensa e, quando da remoção de tecido cariado, teve exposição pulpar. A paciente não tem mais nenhum molar inferior e não faz uso de prótese. Se o dente 38 apresentar dor, não nos resta outra alternativa a não ser a exodontia, pois não se indica endodontia em terceiros molares. Falar para a paciente que o único dente que ele tem para morder está condenado, 
ou que não tem tratamento a ser oferecido não é muito fácil. (Margarida)

Por que a Política Nacional de Saúde Bucal não garante a oferta de próteses fixas no CEO? Não sei se ocorre dessa maneira em todo o país, mas a avaliação externa do PMAQ-CEO em São Paulo evidenciou a inexistência da confecção de próteses fixas no estado. (Orquídea)

A articulação dos serviços é imprescindível para a instauração da clínica ampliada (Campos et al., 2014), e a "desarticulação" encontrada no cenário de estudo se constituiu em fator limitante para a investigação, visto que comprometeu, nesse aspecto, o modelo proposto.

Outros limites foram encontrados na categoria divisão do trabalho, em que foram agrupadas questões relacionadas aos recursos humanos auxiliares e suas atribuições. Emergiram dos diários de pesquisa a escassez e a importância da qualificação do pessoal auxiliar - auxiliar de saúde bucal (ASB) e TSB. Os trechos que seguem ilustram esse achado:

Foram muitos os episódios que evidenciaram os problemas relacionados às ASB/TSB. Em um determinado dia, pedimos a ela [TSB] que fizesse profilaxia de alguns pacientes e ela fugiu (acredito que ela tenha receio de realizar os procedimentos clínicos de sua competência). (Orquídea)

Uma auxiliar bem qualificada contribui muito. (Margarida)

Sem a presença de boas ASB, o trabalho fica mais lento, a biossegurança mais difícil de ser mantida e a qualidade dos procedimentos pode cair. (Violeta)

Para Campos (2003), a clínica ampliada exige a partilha de dúvidas e incertezas com outros profissionais. Ou seja, a divisão técnica do trabalho precisa ser incorporada às práticas de saúde bucal, agregando profissionais auxiliares e técnicos às ações rotineiras para assumir parcelas do atendimento, em espaços físicos compatíveis (Botazzo, 2013). Além disso, os CCP exigem um trabalho interprofissional colaborativo (Walji;
Karimbux; Spielman, 2017), que constitui uma das diretrizes da formação odontológica em diversos países, como afirmam Palatta et al. (2017). Em decorrência disso,

Romper esse monopólio implica superar a referência teórico-metodológica que sustenta essa prática, propondo simultaneamente a divisão técnica do trabalho odontológico e substituindo o trabalho individual do dentista pela equipe de saúde bucal. Ainda deve ser considerado que conteúdos odontológicos devem não apenas ser incorporados por outras práticas de saúde, mas também dissolvidos na cotidianidade das práticas que se dão nos espaços socialmente reconhecidos. Isto não significa a descaracterização da odontologia como prática de saúde específica. Significa, apenas, aproximar-se das outras práticas, significa "perder-se" no turbilhão do movimento sanitário para encontrar-se revitalizada, fertilizada por outros saberes e reaparecer não mais como odontologia, mas como parte da Saúde Coletiva, no interior da qual deverá tornar-se operante a modernidade da sua prática. (Botazzo, 2013, p. 63)

É fundamental, ainda, desenvolver práticas interdisciplinares e multiprofissionais, uma vez que o mesmo objeto pode ser visto sob diferentes olhares que aportam saberes diversos, exigindo mútua colaboração para que as intervenções sejam resolutivas e qualificadas, em detrimento da intervenção compartimentada (Botazzo, 2013; Peduzzi et al., 2013; Way et al., 2001), historicamente predominante na odontologia.

Ao considerar que a clínica ampliada de saúde bucal se baseia no uso de tecnologias leves (Merhy, 2013) e é caracterizada pela escuta qualificada e consequente produção de vínculo e subjetividades, a anamnese, com seu diálogo inicial e identificação da queixa que levou o sujeito a procurar auxílio no serviço de saúde, constitui um elemento central nas práticas (Campos et al., 2014). No cenário de estudo, os pesquisadores buscaram ancorar a anamnese no conceito de bucalidade com vistas a permitir o protagonismo do sujeito no processo de cuidado (Botazzo, 2013), o que foi visto pelos pesquisadores como desafio, conforme ilustram os recortes na sequência: 
Estávamos conversando sobre como conduzir uma consulta individual pautada na bucalidade, ampliando a escuta. Não sabemos!...[risos] Fomos pedir ajuda do [...] e ele nos respondeu que basta se interessar pela vida do paciente e interrelacionar as condições de vida com a saúde. Parece fácil? Pois não é. Continuamos perdidos. (Orquídea)

Depois de falarmos sobre temas variados, ficou evidente nossa deficiência para desenvolver uma boa anamnese e um bom exame físico e, mais do que isso, nossa dificuldade em "significar" nossos achados clínicos. Como não temos um roteiro que nos oriente na busca dos sinais clínicos, não estamos conseguindo "sair" da cavidade bucal. (Orquídea)

Estudos evidenciam as dificuldades apresentadas pelos cirurgiões-dentistas para atuar com base nos determinantes sociais do processo saúdedoença (Sabato et al., 2018). No projeto, foram experienciadas duas modalidades de anamnese: individual e coletiva. No primeiro caso, os usuários eram acolhidos em consultórios clínicos da UBS - de enfermagem e/ou medicina - e discorriam sobre sua vida, suas queixas e seus objetivos ao buscar o atendimento. $\mathrm{Na}$ "anamnese coletiva", os sujeitos falavam sobre questões que emergiam a partir de um tema disparador e interagiam com outros usuários, o que auxiliava no fortalecimento do vínculo e intensificava a autonomia. Em seguida, nas duas possibilidades, realizava-se o exame físico com o usuário acomodado na cadeira odontológica, dispensando o uso do odontograma com vistas a "desodontologizar" o atendimento - e, posteriormente, era constituído o caso clínico e o projeto terapêutico singularizado.

A não utilização do odontograma, a princípio, gerou algum desconforto entre os membros da equipe que estavam, até então, acostumados a se conduzir nos primeiros passos com o auxílio desse dispositivo. 0 excerto a seguir retrata essa constatação:

Ainda acho estranho não preencher um odontograma, porque a impressão que tenho é que vou atender a paciente sem conhecer a boca dela [risos]. Acho que é uma questão de prática. (Violeta)
A intenção da equipe de pesquisa era utilizar o prontuário único (PU) dos usuários para registrar os dados clínicos e a evolução do tratamento; porém, essa solicitação não foi compreendida e aceita pelo Serviço de Arquivamento Médico e Estatístico (Same) da UBS, o que impediu o uso do PU. Esse dado reforça que o processo de trabalho em saúde bucal permanece desvinculado do trabalho da equipe de saúde (Pimentel et al., 2012).

Por fim, ainda que os desafios para o desenvolvimento da clínica ampliada de saúde bucal tenham sido numerosos, a satisfação dos usuários foi expressa ao longo de todo o período de atendimento, motivando a equipe a continuar inovando na clínica, e os excertos dos diários reforçam essa colocação:

o paciente [...] ficou satisfeito e feliz quando viu um dos seus dentes anteriores, destruídos por cárie, ganhar forma outra vez. (Orquídea)

O senhor J. se manifestou [após uma anamnese coletiva], dizendo que estava satisfeito com a abordagem feita e que era isso que ele esperava de um serviço de saúde. Disse ainda que, a princípio, não entendeu bem o porquê daquela conversa, mas que agora ele entendia que todas aquelas informações eram importantes para o tratamento deles. (Orquídea)

[0 paciente] fica feliz com o procedimento efetuado, parece que teve atenção, teve resolução naquele momento. (Margarida)

ele gosta muito de ser atendido na unidade. (Margarida)

Finalizando, Sr. J. disse que a reunião foi surpreendente, pois todos eles vêm com uma ideia prévia e que ele nunca presenciou um atendimento com uma conversa aberta em que as pessoas podem se abrir. Apesar de [parecer] “aérea”, ela não é, e tem um propósito maior. (Violeta)

É evidente, a partir da análise dos recortes, que os usuários se expressam satisfeitos, principalmente em função do maior espaço reservado, na clínica ampliada de saúde bucal, para o diálogo e a escuta qualificada e, 
consequentemente, para a resolubilidade alcançada a partir do estabelecimento de abordagens terapêuticas compartilhadas e singularizadas (Campos et al., 2014). Abordagens de CCP, em especial no âmbito da APS, são apontadas como um modelo associado a resultados positivos, tanto na saúde bucal (Rosenzweig et al., 2016) quanto em outras áreas (Starfield, 2011; Walji; Karimbux; Spielman, 2017).

As principais limitações do estudo estiveram ligadas à construção dos registros em diários de pesquisa, visto que, devido à intensidade de demandas da clínica ampliada de saúde bucal, alguns participantes tiveram dificuldades na destinação de tempo para escrita.

\section{Considerações finais}

A experienciação de novos arranjos para a clínica de saúde bucal permitiu a entrada do sujeito, com suas queixas, como centro da atuação e do trabalho da equipe. A partir daí, dispositivos como a escuta ampliada, o acolhimento, as abordagens terapêuticas singularizadas e o vínculo despontaram como essenciais para o exercício de uma prática clínica qualificada e resolutiva.

A consulta, em si mesma, foi revelada como um dispositivo terapêutico e, dessa forma, criou-se um ambiente de cuidado que extrapolou o tecnicismo e o odontocentramento, caminhando em direção a uma relação mobilizadora de novas posturas profissionais e de empoderamento, tanto da equipe de saúde quanto do usuário, proporcionando maior resolubilidade e ressignificação das práticas.

A construção de propostas terapêuticas que nascem de encontros entre os atores do trabalho foi possível na medida em que se "desaprendia dentes" para aprender "sujeitos”. A estruturação de novas relações de empatia foi fundamental para se perceber o quanto é necessário não chegar pronto ao encontro. Dessa maneira, com a expectativa da descoberta, de parcial abandono de antigas concepções, os pesquisadores se abriram ao novo no campo de coleta de dados, permitindo-se experienciar as práticas desenvolvidas e construir conhecimentos por intermédio da experiência.

O exercício da clínica ampliada de saúde bucal reforçou os limites da PNSB para evitar e solucionar os problemas bucais de usuários reais nem sempre retratados pelos levantamentos epidemiológicos. Os resultados desta pesquisa colocam a imperatividade de rever os protocolos, os fazeres e os saberes arraigados às práticas de saúde bucal de modo a tornálos mais coerentes com as demandas da sociedade brasileira, com os usuários-sujeitos que habitam os territórios de saúde, que sentem, sofrem, gozam e constroem seus caminhos, caminhos estes que nunca podem ser limitados ou reduzidos ao céu da boca.

Como recomendações, aponta-se a necessidade de desenvolver estudos relacionados a novos fazeres em saúde bucal em outras realidades com vistas a aprofundar reflexões, como as que aqui foram colocadas, e aperfeiçoar as práticas existentes.

\section{Referências}

ACFD - ASSOCIATION OF CANADIAN FACULTIES OF DENTISTRY. ACFD educational framework for the development of competency in dental programs. 2016. Disponível em: <https://bit.ly/2SmmMlZ>. Acesso em: 23 out 2018.

APELIAN, N.; VERGNES, J.-N.; BEDOS, C. Humanizing clinical dentistry through a personcentered model. International Journal of Whole Person Care, Montreal, v. 1, n. 2, p. 30-50, 2014.

BARDIN, L. Análise de conteúdo. São Paulo: Edições 70, 2011.

BARROS, R. S.; BOTAZZO, C. Subjetividade e clínica na atenção básica: narrativas, histórias de vida e realidade social. Ciência e Saúde Coletiva, Rio de Janeiro, v. 16, n. 11, p. 4337-4348, 2011.

BOTAZZO, C. Diálogos sobre a boca. São Paulo: Hucitec, 2013.

BOTAZZO, C. O conhecimento pelas mãos. Revista da ABENO, Brasília, DF, v. 17, n. 4, p. 2-19, 2017.

BOTAZZO, C. et al. Inovação na produção do cuidado em saúde bucal: possibilidades de uma nova abordagem na clínica odontológica para o Sistema Único de Saúde: relatório técnico. São Paulo: Fapesp, 2015.

BRASIL. Ministério da Saúde. Secretaria de Atenção à Saúde. Núcleo Técnico da Política Nacional de Humanização. Clínica ampliada, 
equipe de referência e projeto terapêutico singular. 2. ed. Brasília, DF, 2008.CAMPOS, G. W. S. Saúde paidéia. São Paulo: Hucitec, 2003.

CAMPOS, G. W. S. et al. A aplicação da metodologia Paideia no apoio institucional, no apoio matricial e na clínica ampliada. Interface, Botucatu, v. 18, p. 983-995, 2014. Suplemento 1.CECCIM, R. B.; MERHY, E. E. Um agir micropolítico e pedagógico intenso: a humanização entre laços e perspectivas. Interface, Botucatu, v.13, p. 531-542, 2009. Suplemento 1. DOYLE, C.; LENNOX, L.; BELL, D. A systematic review of evidence on the links between patient experience and clinical safety and effectiveness. BMJ Open, London, v. 3, n. 1, eoo1570, 2013.

GLICK, M. et al. A new definition for oral health developed by the FDI World Dental Federation opens the door to a universal definition of oral health. American Journal of Orthodontics and Dentofacial Orthopedics, Saint Louis, v. 151, n. 2, p. 229-231, 2017.

HAYACIBARA, M. F. et al. Experiência de clínica ampliada em odontologia na Universidade Estadual de Maringá. Revista Brasileira de Educação Médica, Brasília, DF, v. 36, n. 1, p. 178-83, 2012. Suplemento 2.

HESS, R. Momento do diário e diário dos momentos. In: SOUZA, E. C.; ABRAHÃO, M. H. M. B. (Org.). Tempos, narrativas e ficções: a invenção de si. Porto Alegre: EdiPUCRS: Eduneb, 2006. p. 89-103.

LOURAU, R. René Lourau na Uerj: 1993: análise institucional e práticas de pesquisa. Rio de Janeiro: Uerj, 1993.

MANOGUE, M. et al. Curriculum structure, content, learning, and assessment in European undergraduate dental education: update 2010. European Journal of Dental Education, Oxford, v. 14, n. 3, p. 133-141, 2011.

MARTELLI, P. J. L. et al. Análise do modelo de atenção à saúde bucal em municípios do estado de Pernambuco. Ciência e Saúde Coletiva, Rio de Janeiro, v. 13, n. 5, p. 1669-1674, 2008.
MENDES, E. V. As redes de atenção à saúde. Ciência e Saúde Coletiva, Rio de Janeiro, v. 15, n. 5 , p. 2297-2305, 2010.

MERHY, E. E. $\mathrm{O}$ ato de governar as tensões constitutivas do agir em saúde como desafio permanente de algumas estratégias gerenciais. Ciência e Saúde Coletiva, Rio de Janeiro, v. 4, n. 2, p. 305-314, 1999.

MERHY, E. E. Ver a si o ato de cuidar. In: CAPOZZOLO, A. A.; CASETTO, S. J.; HENZ, A. O. (Org.). Clínica comum: itinerários de uma formação em saúde. São Paulo: Hucitec, 2013. p. 248-267.

PALATTA, A. M. et al. Change is here: ADEA CCI 2.0-A learning community for the advancement of dental education. Journal of Dental Education, Washington, v. 81, n. 6, p. 640-648, 2017.

PARK, S. E.; HOWELL, T. H. Implementation of a patient-centered approach to clinical dental education: a five-year reflection. Journal of Dental Education, Washington, v. 79, n. 5, p. 523-529, 2015.

PEDUZZI, M. et al. Educação interprofissional: formação de profissionais de saúde para o trabalho em equipe com foco nos usuários. Revista da Escola de Enfermagem da USP, São Paulo, v. 47, n. 4, p. 977-983, 2013.

PETERSEN, P. E. Strengthening of oral health systems: oral health through primary health care. Medical Principles and Practice, Basel, v. 23, p. 3-9, 2014. Suplemento 1.

PEZZATO, L. M.; L’ABBATE, S. Uma pesquisaação-intervenção em saúde bucal coletiva: contribuindo para a produção de novas análises. Saúde e Sociedade, São Paulo, v. 21, n. 2, p. 386-398, 2012.

PIMENTEL, F. C. et al. Caracterização do processo de trabalho das equipes de saúde bucal em municípios de Pernambuco, Brasil, segundo porte populacional: da articulação comunitária à organização do atendimento clínico. Cadernos de Saúde Pública, Rio de Janeiro, v. 28, p. 146-157, 2012. Suplemento.

PIRES, F. S.; BOTAZZO, C. Organização tecnológica do trabalho em saúde bucal no SUS: uma arqueologia da política nacional de saúde 
bucal. Saúde e Sociedade, São Paulo, v. 24, n. 1, p. 273-284, 2015 .

ROSENZWEIG, J. et al. Effect of a person-centered course on the empathic ability of dental students. Journal of Dental Education, Washington, v. 8o, n. 11, p. 1337-1348, 2016.

SABATO, E. et al. Integrating social determinants of health into dental curricula: an interprofessional approach. Journal of Dental Education, Washington, v. 82, n. 3, p. 237-245, 2018.

SHAY, L. A.; LAFATA, J. E. Where is the evidence? A systematic review of shared decision making and patient outcomes. Medical Decision Making, Thousand Oaks, v. 35, n. 1, p. 114-132, 2015.

SOARES, F. F. et al. Atuação da equipe de saúde bucal na estratégia saúde da família: análise dos estudos publicados no período de 2001 a 2008.

Ciência e Saúde Coletiva, Rio de Janeiro, v. 16, n. 7, p. 3169-8o, 2011.

SOUZA, G. C. et al. Referência e contra referência em saúde bucal: regulação do acesso aos centros de especialidades odontológicas. Revista de Salud Pública, Bogotá, v. 17, n. 3, p. 416-428, 2015.

STARFIELD, B. Is patient-centered care the same as person-focused care? Permanente Journal, Portland, v. 15, n. 2, p. 63-69, 2011.

STEWART, M. et al. Medicina centrada na pessoa: transformando o método clínico. 2. ed. Porto Alegre: Artmed, 2010.

WALJI, M. F.; KARIMBUX, N. Y.; SPIELMAN, A. I. Person-centered care: opportunities and challenges for academic dental institutions and programs. Journal of Dental Education, Washington, v. 81, n. 11, p. 1265-1272, 2017.

WATT, R.; SHEIHAM, A. Inequalities in oral health: a review of the evidence and recommendations for action. British Dental Journal, London, v. 187, n. 1, p. 6-12, 1999.

WAY, D. et al. Primary health care provided by nurse practitioners and family physicians in shared practice. Canadian Medical Association Journal, Ottawa, v. 165, n. 9, p. 1210-1214, 2001.

\section{Contribuição dos autores}

Junqueira e Botazzo conceberam o estudo. Fonsêca, Schneider Pires e Souza elaboraram o aporte teórico para discussão dos resultados e, com Botazzo, analisaram os dados obtidos. Todos os autores contribuíram para a redação do artigo, e Junqueira foi responsável pela revisão final do texto.

Recebido: $27 / 06 / 2018$

Aprovado: 09/08/2018 